\title{
Evidenciação de informações socioambientais: um estudo nas organizações do Centro Industrial Subaé, Feira de Santana, Estado da Bahia, Brasil
}

\section{Herval da Silva Moura ${ }^{1}$ e Juliano Almeida de Faria ${ }^{2}$}

\author{
${ }^{1}$ Universidade Estadual de Feira de Santana. Departamento de Ciências Sociais. \\ Colegiado de Ciências Contábeis. Av. Transnordestina, S/№. Novo Horizonte. Feira \\ de Santana-BA, Brasil (CEP 44036-900). E-mail: mourash@terra.com.br. \\ ${ }^{2}$ Universidade Federal de Sergipe. Departamento de Ciências Contábeis. Campus \\ Prof. Alberto Carvalho. Av. Vereador Olímpio Grande. Itabaiana-SE, Brasil (CEP \\ 49506-036).
}

Resumo. A competitividade tem sido fator determinante para despertar nas empresas dos mais diversos portes concepções de que o uso desordenado do meio ambiente provoca um desequilíbrio onde estão inseridas. Neste sentido as empresas têm buscado repensar sua forma de gerenciamento ambiental e, por conseguinte, se veem impulsionadas a evidenciar o seu posicionamento diante deste cenário. Por isto a contabilidade, enquanto área de conhecimento influenciada por fatores, econômicos, políticos e sociais, busca cumprir sua finalidade ao propiciar o fornecimento de informações que sejam úteis aos seus diversos usuários na tomada de decisão, como informações socioambientais de natureza monetária e não-monetária. Tais informações são fornecidas por meio de relatórios que visam a assegurar a transparência das ações organizacionais, além de iniciar o diálogo das mesmas com a sociedade. Nesta perspectiva, o objetivo deste estudo é demonstrar quais as informações contábeis socioambientais são evidenciadas pelas empresas industriais que fazem parte do Centro Industrial Subaé (CIS), no Município de Feira de Santana (Estado da Bahia, Brasil). A pesquisa é classificada como exploratória, bibliográfica e quali-quantitativa. Quanto aos procedimentos, classifica-se como um levantamento por meio de entrevista estruturada. Como resultados, observa-se que o tratamento dado aos gastos ambientais pelas empresas participantes da pesquisa ainda são superficiais, pois não são amplamente conhecidos pelas empresas do CIS. As estratégias de evidenciação ambiental utilizadas, quando existem, são associadas às filiais cuja divulgação é centralizada na matriz, não localizada em Feira de Santana. Por fim, conclui-se que a sociedade carece de informações relacionadas aos gastos ambientais, haja vista baixo nível de evidenciação local. Esta situação revela potencial para desenvolvimento de futuras pesquisas e desenvolvimento de projetos de fomento ao estudo dos custos ambientais e respectivo fluxo de evidenciação à comunidade.
Recebido:

29/08/2019

Aceito:

$30 / 12 / 2019$

Publicado:

$31 / 12 / 2019$

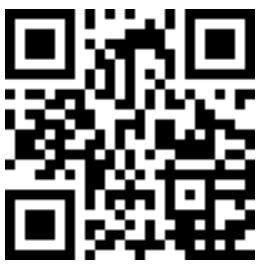

Acesso aberto

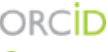

(D) 0000-0002-5527-8275 Herval da Silva Moura

D 0000-0002-0143-9790 Juliano Almeida de Faria 
Palavras-chave: Gestão ambiental; Informações socioambiental; Relatórios de Sustentabilidade; Evidenciação.

Abstract. Disclosure environmental information: A study in Industrial Center organizations Subaé, Feira de Santana, Bahia State, Brazil. Competitiveness has been a determining factor in awakening in companies of the most diverse conceptions that the disorderly use of the environment causes an imbalance in the environment in which they are inserted. In this sense, companies have sought to rethink their form of environmental management and, therefore, they are driven to show their position in this scenario. For this reason, accounting, as an area of knowledge influenced by economic, political and social factors, seeks to fulfill its purpose by providing information that is useful to its users in decision making, such as socio-environmental information of a monetary and non-monetary policy. Such information is provided through reports that aim to ensure the transparency of organizational actions, as well as initiate their dialogue with society. In this perspective, the objective of this study is to demonstrate which socio-environmental accounting information is evidenced by the industrial companies that are part of the Subae Industrial Center (CIS) in the Municipality of Feira de Santana, Bahia State, Brazil. The research, of an applied nature, is classified as an exploratory, bibliographical and qualiquantitative research. As for the procedures, it is classified as a survey through a structured interview. As a result, it can be observed that the treatment given to environmental expenditures by the companies participating in the research is still superficial since environmental expenditures are not widely known by CIS companies. The environmental disclosure strategies used, when they exist, are associated to the subsidiaries whose disclosure is centralized in the matrix, not located in Feira de Santana. Finally, it is concluded that society lacks information related to environmental expenditures due to the low level of local evidence. This situation reveals potential for the development of future research and development of projects to promote the study of environmental costs and the respective flow of evidence to the community.

Keywords: Environmental management; Environmental information; Sustainability Reports; Disclosure.

\section{Introdução}

As preocupações ambientais que permeiam a sociedade do século XXI há alguns anos deixaram de ser objeto de atenção apenas de organizações nãogovernamentais e de ambientalistas para ser foco de discussão, análise e inquietação das organizações mundiais. Por outro lado, a globalização da economia e o aumento da competitividade entre as empresas as conduzem a concentração de esforços para obtenção da qualidade e a busca de diferencial competitivo para produtos e/ou serviços por ela prestados (Gray, 2002; Deegan, 2002; Parker, 2011).

Pode-se afirmar que no contexto atual os cuidados com os problemas socioambientais tornam-se importantes 
para conquistar a confiança do mercado consumidor e, por consequência aquisição de melhores resultados. "Permuta-se [...] a economia baseada na manufatura por uma economia que aproveita metas intelectuais corporativas para alcançar vantagem competitiva sustentável" (Kroetz, 2000, p. 80).

Ferreira (2006, p. 16) enfatiza que "[...] o uso dos recursos naturais disponíveis, embora tenha trazido melhora nas condições de vida, trouxe também a poluição, com todos os seus impactos na condição de vida, e também trouxe preocupações quanto às possibilidades futuras de se continuar vivendo". As entidades têm deixado de entender a responsabilidade social como uma despesa ou um ônus para ser considerada como um investimento, que pode reduzir custos e majorar a receita. Por isto, os administradores têm se preocupado cada vez mais com a engenharia do processo produtivo e com a cadeia produtiva como um todo, ou seja, repensando seus produtos, processos, parceiros e tecnologias incluso na perspectiva do seu cliente final, do seu concorrente, dos seus potenciais parceiros e financiadores.

Nota-se que a sociedade vem exigindo posicionamento das organizações e uma forma de atuar mais responsável com relação às atividades que desenvolvem, visto que é inevitável a utilização dos recursos do meio ambiente e, desta forma, é fundamental o seu uso consciente. Para que a organização tenha boa reputação no aspecto social e ambiental, é importante que conduza as ações com transparência e confiabilidade (Parker, 2011; Ferreira et al., 2016).

As empresas refletem muitos índices que afetam de forma direta a sociedade e seus componentes, porque a sociedade vem sofrendo transformações profundas nas mais diversas áreas, as quais exigem informações confiáveis e principalmente transparência por parte das empresas para que elas possam atuar de forma mais efetiva e eficiente (Kraemer, 2010). A Contabilidade como
Ciência Social, impelida por mudanças econômicas, políticas e sociais, é influenciada por meio destes fatos e cumpre sua finalidade ao propiciar o fornecimento de informações socioambientais, de natureza monetária e não-monetária, das organizações aos seus diversos usuários. Tais informações são instrumentos que visam a garantir a transparência das ações organizacionais, possibilitando o diálogo das mesmas com a sociedade, visto que são apresentados os seus desafios e estratégias e a coerência ética de suas operações.

Para Braga e Pinho (2007) ao disponibilizar as informações o profissional de contabilidade precisa considerar o seu principal objetivo, que é fornecer informações úteis o seu amplo conjunto de usuários para tomada de decisões, contudo, para que haja utilidade nestas informações elas devem atender às características peculiares a qualidade das informações como compreensibilidade, relevância, confiabilidade, comparabilidade e materialidade. Pode-se inferir que as informações socioambientais também precisam possuir tais características uma vez que, além de ser um canal de diálogo entre a entidade e seus usuários, elas podem funcionar como instrumento de marketing interno e externo para as organizações que as publicam.

A crescente demanda pela melhoria da evidenciação dos fatos que afetam não só o meio ambiente, mas também as questões financeiras e econômicas das empresas. No Brasil não há obrigatoriedade da evidenciação da informação ambiental, mas algumas organizações buscam apresentar diretrizes sobre o disclosure ambiental para as empresas (Ferreira et al., 2016). Mesmo não havendo obrigatoriedade, há normas que tentam padronizar a informação ambiental para auxiliar o entendimento. Algumas empresas divulgam separadamente tais informações em relatórios, entretanto, o documento formal obrigatório e utilizado por todas as empresas que estão listadas 
na Comissão de Valores Mobiliários (CVM) são as Demonstrações Financeiras Padronizadas (DFPs) (Ferreira et al., 2016).

Ferreira e Berner (2016) demonstraram existência de déficit de informação ambiental em empresas do ramo de energia elétrica, mesmo considerando a existência de ações de gestão ambiental. Com isso, e sem dispensar a importância da evidenciação ambiental como meio de transparência patrimonial à sociedade, pode-se perceber que a ausência de informações de evidenciação ambiental não significa ausência de ações de gestão ambiental. Cabe, portanto, o entendimento de que é necessário estudar melhor o processo de evidenciação ambiental com vistas ao aumento do volume de informações.

Fonseca et al. (2016), analisaram analisar como evoluiu, em relação a estudos anteriores, a classificação e evidenciação dos custos ambientais em empresas integrantes do setor de papel e celulose listadas no Índice de Sustentabilidade Empresarial (ISE). Os resultados encontrados indicam que as empresas evidenciam seus custos ambientais principalmente na forma qualitativa e do tipo positiva, demostrando que há evolução em relação a estudos anteriores, tanto na qualidade como na quantidade de evidenciação dos custos ambientais. Correia et al. (2017) também confirmaram esta tendência nas empresas de siderurgia onde os resultados apontam que as empresas deste segmento vêm evidenciando de forma crescente e constante itens de cunho socioambiental nos seus relatórios.

Freitag et al. (2016) verificaram a aplicabilidade da Contabilidade Ambiental nas Indústrias Químicas e Farmacêuticas do Paraná, constataram que os contadores dessas indústrias, possuem conhecimento e compreendem a importância da contabilidade ambiental, entretanto não utilizam desta ferramenta de comunicação da interação da empresa com o meio ambiente, devido à falta de obrigatoriedade legal e da falta de percepção sobre retornos referentes a essa adoção e consequente evidenciação.

Já o estudo de Vasconcelos e Pimentel (2018) analisaram como se dá a evidenciação contábil dos custos e investimentos ambientais das empresas consideradas potencialmente poluidoras que compõem a carteira 2016 do ISE da B3. Os resultados apontaram que as empresas da amostra divulgaram as suas informações predominantemente monetárias referentes a custos e 50\% sobre investimentos ambientais nos Relatórios da Administração (90\%) e nas Notas Explicativas. Constatou-se, também, que grande parte das empresas evidenciaram investimentos ambientais do que custos ambientais, um total de $90 \%$ contra $60 \%$. Dentre os custos ambientais mais evidenciados são aqueles referentes às atividades socioambientais.

Nesta perspectiva, este trabalho busca responder ao seguinte problema de pesquisa: Quais as características das informações contábeis socioambientais no que tange a evidenciação de custos ambientais e consequente inserção na formação de preços dos produtos e serviços pelas organizações industriais que fazem parte do Centro Industrial Subaé (CIF) no Município de Feira de Santana - BA?

A partir deste problema, objetivase demonstrar as características da evidenciação de informações contábeis socioambientais produzidas pelas organizações industriais que fazem parte do CIS no município de Feira de SantanaBA. Especificamente: i) mapear o perfil das organizações industriais que compõem o Centro Industrial Subaé no município de Feira de Santana; ii) identificar características do tratamento dado aos gastos ambientais pelas empresas participantes da pesquisa; e iii) identificar as estratégias de evidenciação ambiental utilizadas pelas empresas participantes da pesquisa. 
Discussões fundamentadas na temática estudada podem proporcionar ao meio acadêmico um olhar aos problemas socioambientais que não seja unilateral, mas que pode advertir sobre a necessidade de se considerar outros problemas decorrentes, assinalando um espaço para estudos específicos no contexto do município de Feira de Santana, que enriqueçam o arcabouço teórico institucional acerca da evidenciação de informações socioambientais ainda superficialmente discutidos no meio empresarial do CIS Feira de Santana.

A relevância social que o estudo propõe está atrelada as ações que podem vir a ser planejadas e perpetradas em função da repercussão positiva que a divulgação de demonstrativos contábeis socioambientais é capaz de trazer para as organizações (Deegan, 2002, Ferreira et al., 2016). Outrossim, não se pode perder de vista o estímulo a integração dessas organizações com a sociedade por meio dos projetos; a melhoria da qualidade de vida; a conscientização e corresponsabilidade para com a garantia da perpetuação da vida no planeta, decorrentes da educação socioambiental, e a promoção do bem-estar social.

No que se diz respeito às atividades operacionais desenvolvidas pelas instituições componentes do estudo, a inserção da contabilidade por meio dos registros e evidenciação de assuntos ambientais pode fornecer aos usuários da contabilidade uma a mudança de comportamento por parte das empresas e planos de ação das mesmas em função da ações socioambientais, além de conhecer a estrutura dos custos ambientais por meio de modelo de verificação e assim estudar a viabilidade da inserção destes custos na formação de preços dos produtos.

As informações a serem oferecidas pela contabilidade ambiental devem expor sobre os estudos relativos à melhoria dos processos, no sentido de minimizar os efeitos da poluição, bem como sobre o reaproveitamento de recursos para evitar o desperdício e a degradação do meio ambiente, potencializando vida sustentável e o bem estar de gerações futuras. Sem perder de vista os investimentos feitos pelas organizações no sentido de devolver os recursos naturais danificados através dos custos contingenciais - ressalta-se a importância de se priorizar o planejamento de ações no sentido de evitar que tais danos ocorram. Investimentos em projetos sociais $\mathrm{e}$ ecológicos devem ser entendidos não somente como geradores de custos, mas como diferenciais estratégicos capazes de despertar maior mobilização e participação dos funcionários, a fim de criar vantagens competitivas em relação à concorrência, além de qualificar todo o processo, identificado a entidade cumpridora de suas responsabilidades (Kroetz, 2000).

Para que as informações sejam corretamente evidenciadas nas demonstrações contábeis, sobretudo o custeio ambiental das suas operações, as empresas precisam conhecer seus custos de modo sistematizado e capaz de fornecer informações de qualidade no contexto ao qual está inserido (Freitag et al., 2016). Conhecendo corretamente seus custos as empresas poderão analisar a viabilidade da inserção dos mesmos na formação de preços visto que, desta forma, haverá a contribuição para a melhoria da qualidade da informação contábil para avaliação de resultados e lucratividade de suas operações na região de Feira de Santana.

Ainda assim, com tais informações, as empresas também poderão direcionar mais atenção e recursos para mensurar melhor os impactos ambientais de suas operações na região de Feira de Santana, contribuindo também para a ampliação da transparência empresarial por meio da evidenciação nas demonstrações contábeis. Por fim, a informação de custos ambientais mensurado corretamente poderá contribuir para que 
a empresa tome decisões, a exemplo do que vem ocorrendo no mercado mundial, de promover reservas de recursos (provisões) para contingências ambientais, bem como aquisição de equipamentos para tratamento de dejetos e redução de poluição. Desta forma, a evidenciação de demonstrativos contábeis que guardam relação com a sociedade e meio ambiente exige o contínuo esforço para a garantia da qualidade e ética da comunicação e transparência de ações, sem negligenciar os aspectos relacionados às legislações pertinentes.

\section{Contabilidade Ambiental: origem e conceito}

Com o agravamento das mudanças climáticas no mundo nas últimas décadas muitos países passaram a apresentar uma maior preocupação quanto às questões de cunho socioambiental e, por conseguinte, as organizações se viram impulsionadas a evidenciar o seu posicionamento diante desse cenário. Para que isso de fato ocorresse, contadores, institutos de pesquisa, organismos profissionais e órgãos do governo de vários países passaram a se dedicar no estudo de tais assuntos, com o objetivo de melhorar as informações contábeis sobre o meio ambiente e os impactos ambientais relativos à entidade, através de relatórios financeiros.

O papel da contabilidade diante dessa situação é o de prover informações que encorajem a empresa a caminhar em direção à sustentabilidade e também a inibir resultados que possam afetar negativamente o meio ambiente. Nesse sentido, algumas medidas deveriam ser revistas, tais como as restrições nas práticas orçamentárias; a mensuração do desempenho centrada no lucro de curto prazo; o foco restrito sobre o orçamento de capital e a tomada de decisão para novos produtos e, mais que isso, a contabilidade deveria influenciar na construção de formas de mensuração que levassem em conta não só o aspecto econômico-financeiro, como também o ambiental (Ferreira, 2007).

A partir da concepção de Paiva (2006) pode-se inferir que a contabilidade deve formular parâmetros de mensuração e de registro que permitam o acompanhamento da relação empresa e meio ambiente, bem como a relação econômica e patrimonial decorrente dela. Tal fato se justifica pela função da contabilidade no tempo e na história, visto que é ela quem efetua os registros dos eventos e transações econômicas das empresas através da abordagem sistêmica, gerando os relatórios onde tais informações são disponibilizadas.

Para Tinoco e Kraemer (2011) a contabilidade financeira ambiental tem o objetivo fazer o registro das transações da empresa que impactam o meio ambiente e a sociedade, bem como os efeitos das mesmas que afetam, ou deveriam afetar, a posição econômica e financeira dos negócios da empresa. Entretanto, não se deve deixar de assegurar que os custos, os ativos e os passivos ambientais sejam registrados de acordo com os princípios fundamentais a contabilidade ou, na sua ausência, em consonância com as práticas contábeis geralmente aceitas. Além disso, que o desempenho ambiental tenha a transparência de que os usuários da contabilidade necessitam.

Segundo Kraemer (2006), a Contabilidade Ambiental surgiu na década de 1970, quando as empresas passaram a dar mais atenção aos problemas do meio ambiente, mas só a partir de 1998 adquiriu o status de novo ramo da Ciência Contábil, com a finalização do relatório do Grupo de Trabalho Intergovernamental das Nações Unidas de Especialistas em Padrões Internacionais de Contabilidade e Relatórios (ISAR - United Nations Intergovernanmental Working Group of Experts on International Standards of Accounting and Reporting). 
Ferreira (2006) relata que o desenvolvimento da Contabilidade Ambiental é implicação da necessidade de proporcionar informações apropriadas às características de uma gestão ambiental, entretanto, esta não é uma nova contabilidade, mas uma especificação que fornece um conjunto de informações que relatem adequadamente, em termos econômicos, as ações de uma entidade que alterem seu patrimônio.

A contabilidade ambiental se classifica a partir de três contextos, sendo eles: a contabilidade nacional (com um enfoque macroeconômico); a contabilidade financeira e a contabilidade gerencial (com um enfoque microeconômico). A contabilidade nacional, por sua vez considera $o$ as informações dos recursos naturais da nação, sejam eles renováveis ou não. $\mathrm{A}$ contabilidade financeira se preocupa com a mensuração, avaliação e a informação das responsabilidades ambientais e sua divulgação aos stakeholders. Já a contabilidade gerencial tem por objetivo principal analisar as informações contábeis, para que diante disso venham ser tomadas decisões, nesse caso voltadas para o bem socioambiental.

Segundo Tinoco e Kraemer (2011, p. 149), a contabilidade ambiental e sua gestão, têm como finalidades principais:

- saber se a empresa cumpre com a legislação ambiental vigente;

- ajudar a direção num processo de fixação de gestão ambiental;

- comprovar e informar as evoluções da empresa na atuação ambiental;

- detectar áreas críticas, quanto às questões ambientais;

- se a empresa já possui uma política ambiental: observar se a mesma cumpre com os objetivos ambientais prefixados;

- identificar oportunidades para melhor gestão ambiental;

- identificar estratégias competitivas devido a melhoras de cunho socioambiental
- obter informação específica para fazer frente à solicitação dos stakeholders."

A implementação da contabilidade ambiental numa organização pode evitar as penalidades pelo não cumprimento de exigências legais, satisfazer os usuários dos demonstrativos e reduzir os gastos relativos a custos e despesas operacionais relativos a melhorias na qualidade do processo produtivo e dos produtos. Os benefícios relativos a contabilidade para a gestão ambiental, podem ser voltados tanto para a própria entidade/indústria, quanto para a sociedade como um todo. As indústrias tendem a ganhar principalmente com a redução de custos ligados à produção e com a manutenção de uma boa imagem da mesma, perante a sociedade. Já a sociedade tende a se beneficiar, principalmente, com a prevenção quanto a assuntos ligados ao aquecimento global, ou seja, diminuição da poluição, gastos de energia e água, reflorestamentos, entre outros.

Segundo Kraemer (2002), podese apontar diversas vantagens relacionadas ao uso da contabilidade no enfoque ambiental, tais como:

- Mensuração e alocação dos custos ambientais fundamentados no planejamento ininterrupto de suas aplicações, bem como dos passivos ambientais;

- Utilização intensiva de notas explicativas e investidores de desempenho ambiental;

- Verificação precisa das reduções de recursos naturais utilizados no processo produtivo e demais potenciais do meio físico;

- Análise de custo e benefícios a partir dos valores mensurados pela contabilidade ambiental;

- Comunicação acerca da viabilidade e eficácia econômica dos projetos ambientais;

- Geração de transparência em virtude dos demonstrativos e relatórios evidenciados.

- Ajustes e correções das ações ambientais, reduzindo o nível de agressão à natureza; 
- Qualidade na análise de gestão ambiental da entidade e sua interpretação tanto pelo público interno e externo.

As informações contábeis devem evidenciar informações relevantes, sem exageros que poderiam ofusca a confundir quem estivesse analisando. De acordo Iudícibus (2000), as demonstrações contábeis devem evidenciar todas as informações necessárias, a fim de não torná-las enganosas, sendo disponibilizadas em tempo hábil a fim de possibilitar a tomada de decisão no momento adequado, atendendo o Princípio da Oportunidade.

Hendriksen e Van Breda (2007) definem que a divulgação apropriada é imperativo que se defina primeiro qual é o grupo de usuários da informação. Em segundo lugar, qual o nível da divulgação, o qual é definido fundamentalmente com base no bem estar social decorrente da publicação e em critérios de relevância e precisão. Em terceiro lugar é necessário que se delibere sobre a forma de divulgação, que pode ir além da publicação usual de balanços e demonstrações de resultados. Por fim, é necessário que se escolha o melhor método de publicação, que depende da natureza da informação e de sua importância relativa.

A evidenciação de informações socioambientais prima por tornar pública as informações de cunho econômico, social e ambiental, da entidade para seus acionistas, clientes, entes públicos e toda a sociedade. Conforme Paiva (2006), a evidenciação dos gastos e das provisões realizadas com o meio ambiente é imperativa, bem como aquelas relacionadas diretamente com a natureza que, possivelmente, coloquem em risco os negócios de seus acionistas, e a continuidade da empresa e da sociedade.

\section{Definição e objetivos da contabilidade de custos}

A Contabilidade possui diversos segmentos especializados que visam estudar mais profundamente cada área do conhecimento a qual a mesma pode contribuir, bem como encontrar maneiras de fornecer informações com maior qualidade. Dentre estas e para efeitos deste estudo, encontra-se a contabilidade de custos. A Contabilidade de Custos pode ser entendida como o ramo da ciência contábil que produz informações para os diversos níveis gerenciais de uma entidade, como auxílio às funções de determinação de desempenho, de planejamento e controle de operações e de tomada de decisões (Leone, 2000).

A Contabilidade de Custos irá receber dados, internos e externos, monetários e não-monetários, e acumulá-los de maneira organizada, para que sejam analisados e interpretados com o objetivo de produzir informações de custos para os diversos níveis gerenciais, tendo estas, por sua vez, atender as necessidades dos tomadores de decisões da entidade, abrangendo assim uma diversa área, desde as operações repetitivas até as de natureza estratégica, influenciando também na formulação das principais políticas da organização.

Para Bornia (1995, p. 16), o objetivo do sistema de custos tradicionais resume-se em: "Encontrar os custos dos produtos para avaliação de estoques, permitindo, deste modo, a determinação do resultado da empresa pela contabilidade financeira. Outros objetivos são o auxílio ao controle e auxílio à tomada de decisões." 0 trabalho de Freitas et al. (2007) elucida que os custos ambientais envolvem todos os gastos que se relacionam de modo direto ou indireto com a proteção do meio ambiente e que serão ativados de acordo com sua vida útil, considerando amortização, depreciação e exaustão; aquisição de insumos para controle, redução ou eliminação de poluentes; tratamento de resíduos de produtos; disposição dos resíduos poluentes; 
tratamento de recuperação e restauração das áreas contaminadas e a mão-de-obra utilizada nas atividades de controle, preservação e recuperação do meio ambiente.

A contabilidade de custos tem um papel significativo na atualidade para as empresas, especialmente no Brasil, onde características do mercado atual como concorrência, altos níveis de impostos, redução de emissão de poluentes, proporcionam desafios ao gestor. 0 trabalho de Fenker et al. (2009), realizado com empresas atuantes no Brasil, evidenciou que são necessárias estratégias ambientais funcionais para explorar as oportunidades e minimizar o risco ambiental, naquelas empresas em que isso é relevante. Confirmou-se, também, que há uma correlação positiva entre o nível de riscos ambientais e o de gestão de custos ambientais; além disso, foi verificado que muitas empresas não adotam alguns dos instrumentos de Gestão dos Custos Ambientais recomendáveis, subavaliando os custos ambientais por não considerarem os custos indiretos, intangíveis e contingenciais.

A contabilidade de custos atua neste contexto fornecendo informações estratégicas de modo que seja possível (a) perpetuação da empresa viabilizando o uso consciente de recursos com respectiva redução de custos em todas as áreas, sobretudo para o meio ambiente. Entretanto, o trabalho de Ferreira e Carvalho (2007), realizado com a Central de Separação de Recicláveis (CSR) da Companhia de Limpeza Urbana da Cidade do Rio de Janeiro (COMLURB) evidenciou que as informações enviadas à Prefeitura não permitem analisar as atividades da Central de Separação de Resíduo e muito menos o desempenho do serviço de coleta seletiva. Além disso, após minuciosa análise dos relatórios existentes, embora se possa dizer que o resultado socioambiental é benéfico, ele não é mensurado em termos econômicos pela empresa. Concluindo que não existem relatórios financeiros produzidos pela empresa que sejam capazes de evidenciar os investimentos, gastos e retornos obtidos com o projeto CSR.

Neste contexto apoia-se os objetivos deste projeto de pesquisa no qual busca utilizar os benefícios da contabilidade de custos com o foco no meio ambiente, colocando mais uma vez em o objetivo da contabilidade em execução, pois encontra-se razão da sua existência quando estuda o patrimônio (inclusive o ambiental), gerando informações sobre suas alterações para a tomada de decisão por parte daqueles que detém o poder de interferência no mesmo.

Relatar e mensurar os fatos contábeis relacionados ao uso dos recursos naturais não seria relevante para a Contabilidade caso não afetasse as relações econômicas e, principalmente, o patrimônio das organizações (Ferreira, 2006). Assim sendo, o uso dos recursos naturais torna-se relevante para a Contabilidade por constituir um fator capaz de afetar o patrimônio das entidades. Grande parte das empresas em maior ou menor grau consome recursos naturais para produção e geração de riqueza e nesse contexto, surge um dos maiores desafios da contabilidade, que é conseguir mensurar os danos causados ao meio ambiente (Costa, 1994; Ribeiro, 2006).

Quando produz e vende determinado bem ou serviço, qualquer entidade incorre em gastos, que podem ser diretamente ligados à produção desses ou necessários para a geração das receitas com as vendas dos bens ou serviços (Ribeiro, 2010). Leone (2000) aponta o custo como o consumo de um fator de produção que é medido em termos monetários para obter um produto, serviço ou atividade capaz ou não de gerar renda. Apropriando-se da definição de custos, associa-se a ideia apresentada por Ribeiro (2006) ao inferir que os custos ambientais devem compreender todos aqueles que estiverem relacionados, direta ou 
indiretamente, com a proteção do meio ambiente. Esses custos podem ser relacionados direta ou indiretamente aos benefícios do período em curso.

Por fim, ressalta-se que todas as informações referentes aos eventos e transações envolvidas com a questão ambiental devem ser evidenciadas, com o grau de detalhamento compatível com a relevância dos valores e da natureza dos gastos, ressaltando a relevância do registro dos custos ambientais (Laporta, 2009). Porém, esta realidade parece ser diferente, pois Leonardo (2006) realizou uma pesquisa em indústrias químicas brasileiras certificadas pela ISO 14001 na qual constatou que em sua maioria, não evidenciavam os gastos ambientais nas notas explicativas dos demonstrativos contábeis e quando o faziam geravam informações qualitativas e superficiais.

No estudo de caso desenvolvido por Rossato et al. (2009) tendo como objeto uma empresa de refrigerantes em Santa Maria-RS foi possível concluir que há a separação entre os custos de natureza ambiental e os demais custos da atividade principal da empresa nas demonstrações contábeis, sendo somente evidenciados no Balanço Social anual da entidade. Por fim, o trabalho de (Ribeiro, 2010) identifica que o impacto dos custos de não-preservação ambiental no resultado de uma indústria têxtil na região metropolitana de Natal-RN iria acarretar à empresa um decréscimo no valor da empresa. Tratando-se de uma atividade operacional da empresa e que não é a principal fonte de lucratividade, mesmo assim poderia levá-la a prejuízo com tal multa pecuniária. Penalidade esta que é prevista pela legislação em vigor, podendo até conduzir ao encerramento das atividades da mesma ao apresentar uma multa de valor significativo. Este ambiente remonta um campo fértil para a contabilidade na definição clara dos tipos de gastos socioambientais a fim de que estes sejam devidamente mensurados, registrados e seus impactos diligentemente avaliados (Laporta, 2009). Isto posto tem-se um dos principais desafios para a Ciência Contábil no contexto socioambiental.

Além disso, de acordo com o estudo realizado por Melo e Vieira (2003) os investimentos em preservação do meio ambiente melhoram a imagem da empresa perante a sociedade. A contabilidade fornece demonstrativos contábeis que são instrumentos de prestação de contas e de comunicação das empresas para com a sociedade. Por sua vez, a contabilidade socioambiental apresenta-se como um dos instrumentos de cumprir o papel de trazer a transparência às atividades de impacto socioambiental das organizações e de melhorar sua imagem perante a sociedade. Portanto, reforça-se que o estudo da contabilidade socioambiental é relevante para a formação do profissional contábil, que precisará estar apto a desenvolver sua profissão levando em conta todos os aspectos ambientais no contexto ao qual estiver inserido.

\section{ambiental}

Evidenciação da contabilidade

Para Braga e Pinho (2007) uma entidade pode obter dois tipos de gastos ambientais, os quais são ditos como gastos voluntários ou involuntários. Os gastos voluntários são aqueles, os quais a empresa se antecipa quanto às suas demandas socioambientais, buscando reduzir seus gastos, investindo em tecnologias para a redução de emissão de gases poluentes no planeta, entre outros. Já os gastos involuntários são obtidos por conta de certa falta de prevenção com relação a preocupações ambientais. Diante disso, acabam por acontecer gastos para reparar os danos causados ao meio ambiente. Segundo Paiva (2006, p. 48), "quando a empresa passa a valorizar sua relação com o meio ambiente e a tomar medidas preventivas, sua imagem perante a opinião pública tende a apresentar conotação diferenciada".

Como objetivo principal da evidenciação é garantir a comunicação, sem ruídos, proporcionando àqueles que 
forem usufruir à mesma, esclarecimento quanto às informações ali apresentadas, a partir do momento em que passar a exercer o papel da pró-atividade com relação à gestão ambiental, uma empresa deve evidenciar suas atividades e gastos ambientais através de relatórios contábeis. Desta forma ela poderá transparecer uma imagem fiel dos seus interesses e ambientais e ecológicos. Para alguns estudiosos da área o reconhecimento e a recuperação de áreas degradadas antes de notificação legal, podem assumir caráter de resgate perante a natureza, mas não se caracterizam como ação proativa, visto que na maioria das vezes estas ações ocorrem para livrar as organizações de multas significativas.

Segundo Paiva (2006) os relatórios da administração, as notas explicativas, o ecobalanço, e o balanço social, têm atuado como formas principais de evidenciação socioambiental.

\begin{abstract}
Relatórios da administração Demonstram as provisões ambientais, ou seja, o que foi, é, e vai ser feito pela empresa com relação ao meio ambiente ressaltando os pontos positivos, porém não omitindo os pontos negativos.
\end{abstract}

Notas explicativas - Buscam esclarecer a situação patrimonial da empresa descrevendo suas práticas contábeis, revelando assim fatos importantes que poderiam vir a ameaçar a continuidade da mesma.

Ecobalanço - Compõe o levantamento de informações ambientais ao final de determinado período, com o objetivo de analisar o nível de poluição da empresa no fim do exercício fiscal.

Balanço social - Engloba informações de caráter social e ambiental envolvendo dados de seu exercício presente e dois anteriores para que possa ser feito uma análise dos gastos ambientais feitos pela empresa (PAIVA, 2006).
Em uma abordagem contemporânea, o Tinoco (2010), indica que o Global Reporting Intiative (GRI), estabelece diretrizes para estruturação do Relatório de Sustentabilidade, o qual tem como prática medir, divulgar e prestar contas para stakeholders internos e externos do desempenho organizacional visando ao desenvolvimento sustentável. Entretanto, este relatório ainda é restrito às empresas com ações negociadas em bolsa e que causam grandes impactos no meio ambiente devido ao seu grande porte. Percebeu-se então que a literatura que versa sobre a discussão de informações socioambientais, indica nomenclaturas diversas para relatório que vise retratar a responsabilidade social e ambiental empresarial.

Apesar de saber que cada vez mais a preocupação da sociedade em relação às questões socioambientais se convergem para a adesão de uma modalidade de desenvolvimento que ofereça conforto e qualidade, sem negligenciar a sustentabilidade, qualquer que seja o modelo adotado por uma organização para evidenciar a coerência e zelo da sua gestão responsável, o êxito das ações e projetos implementados só acontecerá se houver um esforço conjunto dos elementos envolvidos no sentido de efetivar as ações que promovam o bem estar geral no futuro

\section{Metodologia}

Este trabalho é classificado como um estudo exploratório, que segundo Gil (2010) "tem como objetivo proporcionar maior familiaridade com o problema, com vista a torná-lo mais explícito ou a constituir hipóteses". Para tanto, caracteriza-se também como um estudo qualitativo-quantitativo, visto que utilizar-se de dados específicos das empresas da amostra dentro do Centro Industrial do Subaé de Feira de Santana Bahia (CIS). Tais dados foram devidamente tabulados e analisados descritivamente pelo Statistical Package 
for the Social Sciences ${ }^{\circledR}$ (SPSS), Versão 20. A pesquisa se caracteriza também como bibliográfica, já que desvenda, recolhe e analisa as principais contribuições teóricas sobre um determinado fato, assunto ou ideia, utilizando-se de dados obtidos por outros autores (Martins e Campos, 2004). Isto coaduna com o presente trabalho, já que este recorre a um conjunto de conhecimentos disponíveis na literatura atual ligados à preocupação socioambiental das empresas para a construção de um arcabouço conceitual sobre o qual se desenvolverá o projeto voltado à região de Feira de Santana.

No que tange a população e amostra, ressalta-se que o CIS-Feira de Santana foi escolhido por reunir a maioria das empresas industriais de Feira de Santana, exercendo assim, entre outros, o papel de fornecedor de informações básicas que viabilizarão o acesso às empresas participantes da pesquisa. Entende-se por Centro Industrial Subaé (CIS), uma área específica para a instalação de indústrias, estrategicamente afastada do centro urbano, mas posicionada de tal forma que garante às suas empresas rápido acesso e um diferenciado escoamento de produção. O CIS está localizado no Município de Feira de Santana e é subdividida em três núcleos: CIS-Tomba, CIS-BR 324 e o núcleo São Gonçalo. 0 núcleo BR-324 compreende uma área de, aproximadamente, $28,4 \mathrm{~km}^{2}$, localizada ao longo da BR 324, no Município de Feira de Santana, com 14,2 km de comprimento, a partir do anel de contorno rodoviário, em direção a salvador, por $1.000,00 \mathrm{~m}$ de largura para cada lado, a contar do limite da faixa de domínio da citada rodovia.

Grande parte das empresas do CIS, estão registradas no Centro Industrial de Feira de Santana, (CIFS). Com 40 anos de existência, esta instituição foi considerada de utilidade pública pela Prefeitura Municipal, diante do importante papel exercido no contexto econômico regional. As informações cadastrais básicas da população estão disponíveis no site do CIFS que serviu de base para a montagem do cadastro inicial. Com isso, foi possível trabalhar a amostra de acordo com os objetivos específicos deste projeto. A população é formada por todas as empresas cadastradas no CIFS, totalizando 149 empresas. Todas as empresas foram convidadas a participar da pesquisa, obtendo um retorno de 42 empresas (28,19\%), pelas quais se compõe a amostra as empresas.

Para atingir o objetivo específico 1, mapear o perfil das organizações industriais que compõem o Centro Industrial Subaé no município de Feira de Santana investigando as ações de redução de impactos ambientais divulgadas (ou não) por meio de relatórios de sustentabilidade, foi realizado um levantamento de todas as informações cadastrais disponíveis no site do CIFS sobre as empresas associadas. Com base nestes dados, todas as empresas foram convidadas a participar da pesquisa por meio de contato telefônico prévio e posterior envio do questionário por endereço eletrônico para o gestor principal e/ou proprietário da empresa. 0 questionário composto por afirmações diretas e por meio da escala Likert (1932) de cinco pontos, foi construído e aplicado de modo a viabilizar a coleta dos dados e atendimento dos demais objetivos específicos.

\section{Resultados}

Os resultados iniciais de análise do perfil das empresas cadastradas no CIFS são apresentados na Tabela 1.

Tabela 1. Classificação quanto a atividade econômica - CNAE. 


\begin{tabular}{c|c|l|c|c}
\hline Seção & Divisões & \multicolumn{1}{c|}{ Descrição CNAE } & F & \% \\
\hline A & $01 . .03$ & Agricultura, pecuária, produção florestal, pesca e aquicultura & 0 & 0,00 \\
\hline B & $05 . .09$ & Indústrias extrativas & 1 & 0,67 \\
\hline C & $10 . .33$ & Indústrias de transformação & 135 & 90,60 \\
\hline D & $35 . .35$ & Eletricidade e gás & 0 & 0,00 \\
\hline E & $36 . .39$ & Água, esgoto, atividades de gestão de resíduos e descontaminação & 9 & 6,04 \\
\hline F & $41 . .43$ & Construção & 4 & 2,68 \\
\hline \multicolumn{2}{l}{ Total }
\end{tabular}

A quantidade de indústrias de transformação representando 90,60\% das empresas da população compreende o foco da análise das pesquisas, uma vez que é nas indústrias em que ocorre o maior volume de geração de resíduos e, consequentemente, impactos no meio ambiente.

Tabela 2. Quantidade de funcionários.

\begin{tabular}{l|c|c}
\hline \multicolumn{1}{c|}{ Quantidade de Funcionários } & Frequência & $\mathbf{\%}$ \\
\hline $1-10$ & 38 & 25,50 \\
\hline $11-20$ & 29 & 19,46 \\
\hline $21-50$ & 38 & 25,50 \\
\hline $51-100$ & 16 & 10,74 \\
\hline $101-500$ & 23 & 15,44 \\
\hline Mais de 500 & 5 & 3,36 \\
\hline Total & 149 & 100 \\
\hline
\end{tabular}

Na Tabela 2 chama-se a atenção para o perfil das empresas com até 10 funcionários e com quantidade de funcionários entre 21 e 50, representando potencial de impacto das empresas no que tange a representatividade social na cidade. A quantidade de funcionários auferida refere-se apenas a empregados diretos e aponta para desenvolvimento de benefícios aplicados à sociedade quanto à evidenciação contábil e geração de informações ambientais.

A Tabela 3 apresenta o resumo quantitativo dos dados coletados das 42 empresas participantes da pesquisa bem como os resultados primários das análises estatísticas descritivas geradas pelo SPSS, v. 20. Inicialmente, relaciona-se todas as questões apresentadas no questionário aplicado. Na coluna " $\mathrm{N}$ ", concentram-se os valores dos questionários válidos e na coluna "Missing" os valores das questões cujos valores não foram válidos para aquela questão, conforme será tratado individualmente. As demais colunas, representam a média (Mean), erro padrão da média (Std. Error of Mean), mediana (Median), desvio padrão (Std. Devia.) e variância (Var.), todos mecanismos da análise estatística de qualificação dos resultados calculados. Por fim, a coluna "Min" e "Max." representam os valores, respectivamente, mínimo e máximo possível para resposta de cada questão. Este ajustamento de dados foi necessário para viabilizar os cálculos estatísticos pelo software, ressaltando que esta ação não prejudicou a qualidade nem a veracidade dos valores emanados dos questionários.

Em continuidade a descrição do perfil, observa-se inicialmente os resultados do questionário no que tange o perfil do risco ambiental das empresas da amostra. A Tabela 3 (4 últimas questões) demonstra que $86 \%$ das empresas não dependem de Estudo de Impacto Ambiental (EIA) e de Relatório de Impacto ao Meio Ambiente (RIMA) para 
funcionamento, ambos mecanismos de análise e levantamento de informações de impacto ambiental, fundamentais para suporte na análise contábil e posterior mensuração e registro. Revela também que $81 \%$ das empresas não adotam procedimentos operacionais visando evitar multas e processos judiciais por infração ambiental, o que as coloca num nível ainda mais elevado de risco ambiental que, numa eventual fiscalização ambiental, pode incorrer em valores capazes de comprometer o fluxo de caixa da empresa no curto prazo. Agravante a esta situação é que $100 \%$ das empresas informam que não possuem seguros contra riscos ambientais e que não faz parte da política das empresas (83\%) conceder algum benefício para os funcionários como incentivo pela redução de custos ambientais.

Tabela 3. Conhecimento, registro e evidenciação de informações ambientais.

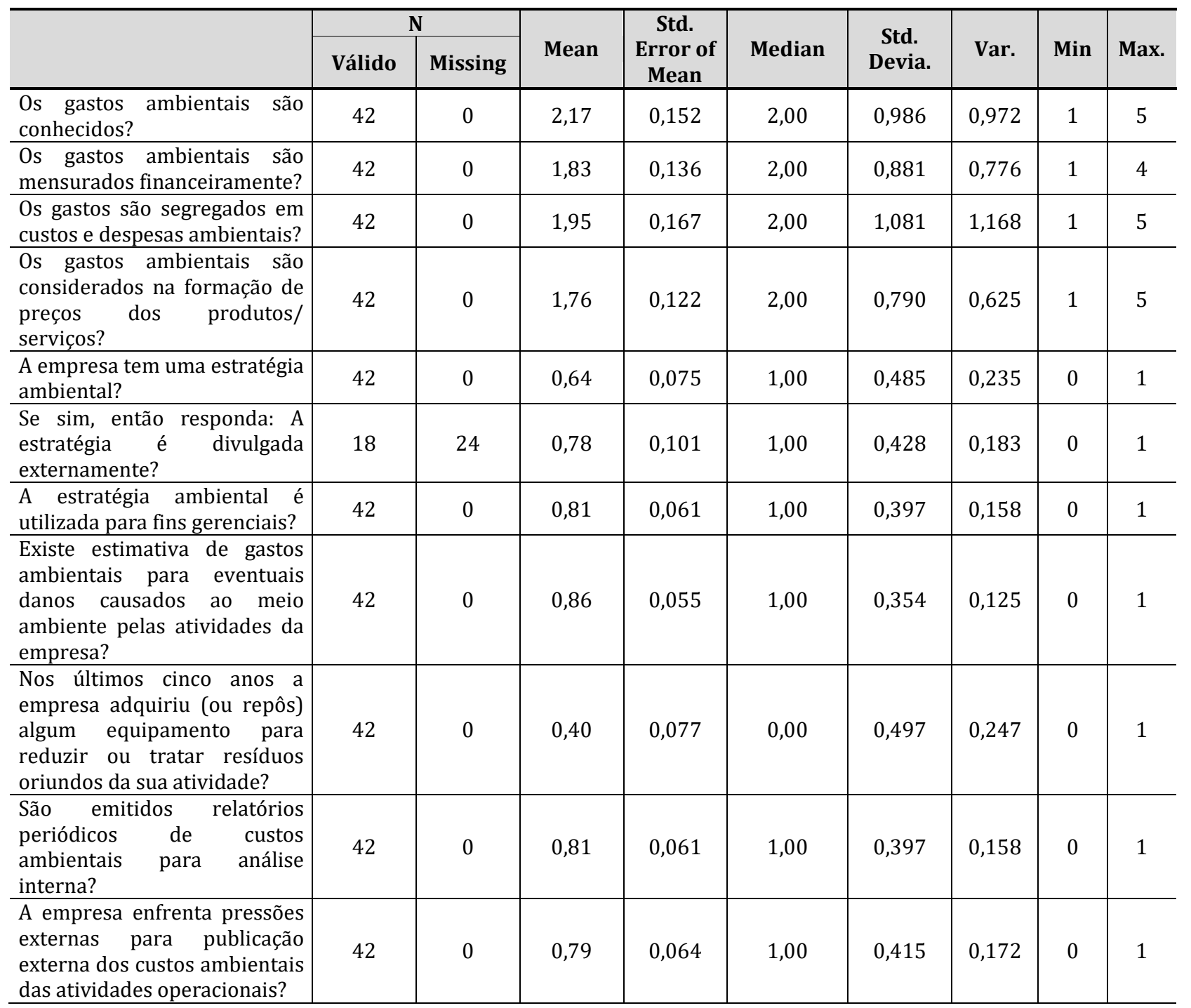


Tabela 3. Continuação.

\begin{tabular}{|c|c|c|c|c|c|c|c|c|c|}
\hline & \multicolumn{2}{|c|}{$\mathbf{N}$} & \multirow{2}{*}{$\begin{array}{c}\text { Mean } \\
0,95\end{array}$} & \multirow{2}{*}{$\begin{array}{c}\begin{array}{c}\text { Std. } \\
\text { Error of } \\
\text { Mean }\end{array} \\
0,033\end{array}$} & \multirow{2}{*}{$\begin{array}{c}\text { Median } \\
1,00\end{array}$} & \multirow{2}{*}{$\begin{array}{c}\begin{array}{c}\text { Std. } \\
\text { Devia. }\end{array} \\
0,216\end{array}$} & \multirow{2}{*}{$\begin{array}{c}\text { Var. } \\
0,046\end{array}$} & \multirow{2}{*}{$\begin{array}{c}\text { Min } \\
0\end{array}$} & \multirow{2}{*}{$\begin{array}{c}\text { Max. } \\
1\end{array}$} \\
\hline $\begin{array}{l}\text { As informações com custos } \\
\text { ambientais da empresa estão } \\
\text { divulgadas na internet? }\end{array}$ & 42 & 0 & & & & & & & \\
\hline 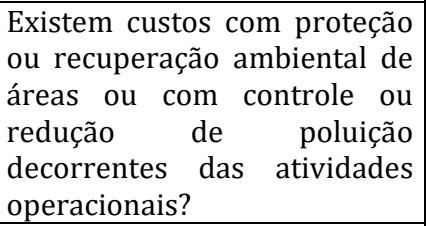 & 42 & 0 & 0,86 & 055, & 1,00 & 0,354 & 0,125 & 0 & 1 \\
\hline $\begin{array}{l}\text { Os custos ambientais são } \\
\text { considerados em novos } \\
\text { projetos de investimento? }\end{array}$ & 42 & 0 & 0,83 & 0,058 & 1,00 & 0,377 & 0,142 & 0 & 1 \\
\hline $\begin{array}{lr}\text { São feitas } & \text { estimativas de } \\
\text { custos } & \text { ambientais } \\
\text { intangíveis? } & \\
\end{array}$ & 42 & 0 & 0,98 & 0,024 & 1,00 & 0,154 & 0,024 & 0 & 1 \\
\hline $\begin{array}{l}\text { Os custos ambientais são } \\
\text { considerados na composição } \\
\text { dos custos totais dos } \\
\text { produtos? }\end{array}$ & 42 & 0 & 0,83 & 0,058 & 1,00 & 0,377 & 0,142 & 0 & 1 \\
\hline $\begin{array}{l}\text { Os custos ambientais são } \\
\text { considerados na política de } \\
\text { formação de preços dos } \\
\text { produtos? }\end{array}$ & 42 & 0 & 0,86 & 0,055 & 1,00 & 0,354 & 0,125 & 0 & 1 \\
\hline $\begin{array}{l}\text { Se sim, então responda: Qual } \\
\text { o nível de relevância destes } \\
\text { no custeio total do produto ou } \\
\text { serviço? }\end{array}$ & 7 & 35 & 2,00 & 0,218 & 2,00 & 0,577 & 0,333 & 1 & 3 \\
\hline $\begin{array}{l}\text { A empresa desenvolve } \\
\text { relatório com informações } \\
\text { sobre custos ambientais? }\end{array}$ & 42 & 0 & 0,83 & 0,058 & 1,00 & 0,377 & 0,142 & 0 & 1 \\
\hline $\begin{array}{l}\text { Informações de custos } \\
\text { ambientais são conhecidas? }\end{array}$ & 42 & 0 & 0,81 & 0,061 & 1,00 & 0,397 & 0,158 & 0 & 1 \\
\hline $\begin{array}{l}\text { Se sim, então responda: Estas } \\
\text { informações são divulgadas } \\
\text { externamente? }\end{array}$ & 19 & 23 & 1,00 & 0,000 & 1,00 & 0,000 & 0,000 & 1 & 1 \\
\hline $\begin{array}{l}\text { A empresa obtém receita com } \\
\text { a comercialização de resíduos } \\
\text { do processo produtivo (sub- } \\
\text { produto)? }\end{array}$ & 42 & 0 & 0,55 & 0,078 & 1,00 & 0,504 & 0,254 & 0 & 1 \\
\hline $\begin{array}{l}\text { Se sim, então responda: Estas } \\
\text { informações são divulgadas } \\
\text { externamente? }\end{array}$ & 27 & 15 & 0,89 & 0,062 & 1,00 & 0,320 & 0,103 & 0 & 1 \\
\hline $\begin{array}{lrr}\text { Se } \quad \text { sim, é } & \text { divulgada } \\
\text { externamente } & \text { então } \\
\text { responda: } & \text { Com } & \text { qual } \\
\text { frequência essas informações } \\
\text { são divulgadas externamente? }\end{array}$ & 3 & 39 & 1,00 & 0,000 & 1,00 & 0,000 & 0,000 & 1 & 1 \\
\hline $\begin{array}{lr}\text { Os custos ambientais } & \text { são } \\
\text { confrontados com } & \text { o } \\
\text { faturamento da empresa? } & \\
\end{array}$ & 42 & 0 & 0,88 & 0,051 & 1,00 & 0,328 & 0,107 & 0 & 1 \\
\hline
\end{tabular}


Tabela 3. Continuação.

\begin{tabular}{|c|c|c|c|c|c|c|c|c|c|}
\hline & \multicolumn{2}{|c|}{$\mathbf{N}$} & Mean & $\begin{array}{l}\text { Std. } \\
\text { Error of }\end{array}$ & Median & $\begin{array}{c}\text { Std. } \\
\text { Devia. }\end{array}$ & Var. & Min & Max. \\
\hline $\begin{array}{l}\text { A empresa depende de Estudo } \\
\text { de Impacto Ambiental (EIA) e } \\
\text { Relatório de Impacto ao Meio } \\
\text { Ambiente (RIMA) para } \\
\text { funcionar? }\end{array}$ & 42 & 0 & 0,86 & 0,055 & 1,00 & 0,354 & 0,125 & 0 & 1 \\
\hline $\begin{array}{l}\text { Procedimentos operacionais } \\
\text { são adotados visando evitar } \\
\text { multas por infração ambiental } \\
\text { e processos judiciais? }\end{array}$ & 42 & 0 & 0,81 & 0,061 & 1,00 & 0,397 & 0,158 & 0 & 1 \\
\hline $\begin{array}{l}\text { A empresa possui seguro } \\
\text { contra riscos ambientais? }\end{array}$ & 42 & 0 & 1,00 & 0,000 & 1,00 & 0,000 & 0,000 & 1 & 1 \\
\hline $\begin{array}{l}\text { Os funcionários recebem } \\
\text { benefícios pela redução de } \\
\text { custos ambientais? }\end{array}$ & 42 & 0 & 0,83 & 0,058 & 1,00 & 0,377 & 0,142 & 0 & 1 \\
\hline
\end{tabular}

O primeiro bloco de questões buscou identificar os impactos ambientais das operações das empresas na região e seus respectivos custos ambientais inerente a cada atividade por meio de uma análise mais específica sobre o tratamento dos gastos ambientais pelas empresas. Por meio da escala Likert (1932) de cinco pontos, o resultado de 2,17 para a primeira questão demonstra que as empresas da amostra pouco conhecem os gastos ambientais pelo fato da média $(2,17)$ estar abaixo do valor da zona indecisão compreendido no número 3 . Valores acima de 4 até 5 representariam o maior nível de conhecimento dos gastos ambientais.

Tal situação demonstra a urgente necessidade das empresas buscarem investir no processo de conhecimento dos gastos ambientais, de modo que os mesmos possam ser registrados pela contabilidade e assim fazer parte do fluxo de informação contábil para mensuração do patrimônio. Sem esta etapa devidamente cumprida a contabilidade fica impossibilitada de gerar informações para tomada de decisão sobretudo no aspecto ambiental. Considerando que os gastos ambientais interferem no patrimônio, então interessam à contabilidade e devem ser, portanto, mensurados e registrados (Ferreira, 2006).

Além disso, como possíveis motivos para este resultado, pode-se relacionar falta de recursos, falta de interesse sobre o assunto e até mesmo desconhecimento da possibilidade de mensuração dos gastos ambientais pela contabilidade. Quaisquer que sejam os motivos, a realidade constatada na amostra revela atraso diante das necessidades cada vez mais urgentes de ações das empresas para com o meio ambiente na qual atuam, sem as quais não serão possíveis sem o conhecimento dos gastos ambientais.

Quanto a ação de mensuração financeira dos gastos, o resultado ainda é inferior, atingindo uma média de 1,83 (Máximo de 5), resultado no qual tornase possível em função, principalmente, da questão anterior, uma vez que não se é possível mensurar financeiramente quando os gastos ambientais não são conhecidos. Já a questão acerca da segregação dos gastos entre custos e despesas ambientais a média de 1,95 reforça o resultado da questão anterior e vai de encontro aos resultados apresentados por Rossato et al. (2009). Também apoia o resultado da questão seguinte, na qual apresenta 1,76 de média ao questionar se as empresas 
utilizam os gastos ambientais para formação de preços dos produtos e serviços.

Com base nestes resultados iniciais as empresas da amostra demonstram baixo nível de conhecimento acerca dos gastos ambientais o que limita as empresas de obter as vantagens da contabilidade ambiental apresentadas por Tinoco (2009) e Kraemer (2002). Com isso, a continuidade das empresas pode estar comprometida sobretudo por estarem transferindo para o mercado produtos com valores que não refletem os custos reais das suas operações. Ressalta-se ainda que os gestores tem tomado decisões de cunho econômico restritas às limitadas informações as quais dispõe que, por sua vez, não contemplam os impactos ambientais nem os gastos inerentes ao mesmo, contribuindo negativamente para o meio ambiente na cidade de Feira de Santana.

Quando a identificação da presença de uma estratégia ambiental nas empresas da amostra, $64 \%$ das empresas dizem que não dispõem e, das que detêm uma estratégia ambiental, $78 \%$ não divulgam para a comunidade. Além disso, 81\% afirmam que a estratégia ambiental não é utilizada para fins gerenciais, ou seja, não está atrelada ao processo de tomada de decisão. A constituição de uma estratégia ambiental pode contribuir para a empresa organizar-se e destinar recursos para mensuração dos gastos ambientais, análise das perdas e impactos envolvidos no contexto operacional, ações de mitigação destas perdas/impactos e maximização da qualidade da imagem da empresa junto à comunidade em que atua, neste caso, em Feira de Santana, por meio da divulgação das suas ações e estratégias. Tais resultados confrontam as ideias defendidas por Laporta (2009) mas confirmam os resultados apresentados por Leonardo (2006), demonstrando que as empresas ainda têm um caminho longo no que tange a evidenciação ambiental.
No próximo bloco de questões analisa-se as ações das empresas da amostra diante da urgente necessidade de conhecimento dos impactos ambientais causados por suas operações. Como resultado, ressalta-se que $86 \%$ das empresas da amostra não realizam estimativas de gastos ambientais para eventuais danos causados ao meio ambiente por suas atividades. Por outro lado, $60 \%$ das empresas da mostra atestam que adquiriu ou repôs nos últimos cinco anos algum equipamento para reduzir ou tratar resíduos oriundo da sua atividade. Este resultado demonstra uma situação menos grave pois, parte das empresas vem colocando os impactos ambientais em suas decisões de compra de equipamentos. Entretanto, ainda é uma situação insuficiente e para atender às necessidades da sociedade com a redução de impactos e geração de mais informações de cunho ambiental.

Corroborando com esta tendência da amostra, $81 \%$ das empresas não emitem relatórios periódicos de custos ambientais para análise interna, demonstrando ausência de registros organizados de custeio ambiental. Esta situação permite concluir que que as empresas podem não compreender todos custos relacionados, direta ou indiretamente, com a proteção do meio ambiente, e assim vão de encontro às ideias já defendidas por Ribeiro (2006) há mais de 20 anos. Parte disso pode ser explicado pelo fato de empresários proprietários de pequenas e médias empresas não se considerarem poluidores além de revelarem carência significativa de conhecimento sobre assuntos relacionados a prática de gestão ambiental nestas empresas.

Por outro lado, $79 \%$ das empresas declaram não receber pressões externas para publicação externa dos custos ambientais das atividades operacionais. Neste caso, o papel da sociedade organizada revela-se tímido quanto às exigências para com as empresas situadas no CIS - Feira de Santana. Ressalta-se que a sociedade tem 
um papel protagonista neste contexto uma vez que é a beneficiária direta (empregos diretos e indiretos) dos produtos e serviços oferecidos pelas indústrias do CIS, mas também é a que arca com os impactos ambientais provenientes das operações de produção e transformação (Deegan, 2002). Como consequência direta disso, 95\% das empresas afirmam que não divulgam informações de custos ambientais na rede mundial de computadores. Com isso as empresas (86\%) não direcionam recursos para proteção ou recuperação ambiental, controle ou redução a poluição decorrentes das suas atividades operacionais.

As empresas (83\%) revelam que os custos ambientais não são considerados em novos projetos de investimento e que $(97 \%)$ não realizam estimativas de custos de intangíveis. Tais resultados harmonizam-se com 0 panorama geral da pesquisa até 0 momento, uma vez que empresas desconhecem os gastos (custos e despesas) ambientais e sofrem baixo nível de pressão externa para divulgação ambiental. Além disso, 83\% das empresas não consideram os custos ambientais na composição dos custos totais dos produtos e $85 \%$ os desconsideram para efeito de formação de preço dos produtos. Por outro lado, tais resultados vão de encontro as ideias defendidas por Ribeiro (2006), Leone (2000), Ferreira (2006), Freitag et al. (2016) e Vasconcelos e Pimentel (2018), os quais defendem a total inserção da contabilidade ambiental no fluxo interno de tomada de decisões das empresas. Tal situação leva os gestores a tomadas de decisões com base em informações que não contemplam os gastos ambientais, e que, por sua vez, impactam no patrimônio das empresas, levando-as ao comprometimento da continuidade no longo prazo.

No que tange as características da evidenciação, 83\% das empresas não desenvolvem qualquer mecanismo de evidenciação de custos ambientais. Neste contexto, $81 \%$ das empresas afirmam não conhecer os custos ambientais sendo que, das que conhecem, nenhuma divulga tais informações. Percebe-se que este quadro está apoiado fortemente na ausência de conhecimento das empresas quanto aos custos ambientais e de pressão da sociedade por divulgação de informações ambientais. Assim, faz-se necessário um trabalho conjunto da sociedade organizada, dos empresários, órgãos de regulação e pesquisa para desenvolver caminhos para melhoria da estrutura de evidenciação das informações ambientais, uma vez que pressupõe o conhecimento da empresa destas informações e a melhoria da tomada de decisão, representando ganhos para todos os envolvidos.

Um aspecto que pode agregar valor ao processo é o fato de $45 \%$ das empresas afirmarem que obtém receita com a comercialização de resíduos do processo produtivo comercializados como subprodutos. Entretanto, destas, $89 \%$ das empresas não divulgam tais informações e as que divulgam o fazem apenas anualmente. Neste contexto, pode-se perceber que as empresas buscam maximizar resultados, porém ainda há espaço para ampliação do comércio de subprodutos o que é um fator determinante para redução da geração de resíduos e incentivo da continuidade da empresa ao longo do tempo. Além disso, a evidenciação destas informações pode ampliar as possibilidades das empresas criarem redes comerciais de reaproveitamento beneficiando toda a sociedade.

\section{Conclusão}

0 objetivo deste artigo foi demonstrar as características da evidenciação de informações contábeis socioambientais produzidas pelas organizações industriais que fazem parte do CIS no município de Feira de SantanaBA. Especificamente, o objetivo específico 1 foi mapear o perfil das organizações industriais que compõem o 
Centro Industrial Subaé no município de Feira de Santana. Neste sentido, observou-se $90,60 \%$ da amostra de indústrias de transformação compreendendo o foco da análise das pesquisas, uma vez que ocorre nas indústrias o maior volume de geração de resíduos e, consequentemente, impactos no meio ambiente. Destas, $86 \%$ das empresas não dependem de Estudo de Impacto Ambiental (EIA) e de Relatório de Impacto ao Meio Ambiente (RIMA) para funcionamento, ambos mecanismos de análise e levantamento de informações de impacto ambiental, fundamentais para suporte na análise contábil e posterior mensuração e registro.

As empresas da amostra não adotam procedimentos operacionais visando evitar multas e processos judiciais por infração ambiental, o que as coloca num nível ainda mais elevado de risco ambiental que, numa eventual fiscalização ambiental, pode incorrer em valores capazes de comprometer o fluxo de caixa da empresa no curto prazo. Agravante a esta situação é que 100\% das empresas informam que não possuem seguros contra riscos causados ao meio ambiente.

No que tange o objetivo específico 2, identificar características do tratamento dado aos gastos ambientais pelas empresas participantes da pesquisa; e objetivo específico 3, identificar as estratégias de evidenciação ambiental utilizadas pelas empresas participantes da pesquisa, pode-se observar que as empresas da amostra pouco conhecem os gastos ambientais e pouco mensuram financeiramente os gastos, desencadeando e justificando parte dos resultados gerais identificados nesta pesquisa.

Com a ausência $(64 \%$ das empresas) de uma estratégia ambiental percebe-se que a estratégia ambiental não é utilizada para fins gerenciais, ou seja, não está atrelada ao processo de tomada de decisão. Das que dispõe de estratégia (78\%) preferem não divulgar para a comunidade prejudicando o processo de evidenciação para a comunidade. Podendo afirmar que, consequentemente, as empresas da amostra não realizam estimativas de gastos ambientais para eventuais danos causados ao meio ambiente por suas atividades. Por outro lado, $60 \%$ das empresas da mostra atestam que adquiriu ou repôs nos últimos cinco anos algum equipamento para reduzir ou tratar resíduos oriundo da sua atividade.

Deste quadro identificado ainda obteve-se o resultado de $81 \%$ relacionado às empresas que não emitem relatórios periódicos de custos ambientais para análise interna, demonstrando ausência de registros organizados contabilmente de custeio ambiental assim como o desuso da mensuração dos custos ambientais em novos projetos de investimento não realização de estimativas de custos de intangíveis. Por fim, 83\% das empresas não consideram os custos ambientais na composição dos custos totais dos produtos e $85 \%$ os desconsideram para efeito de formação de preço dos produtos. $83 \%$ das empresas não desenvolvem qualquer mecanismo de evidenciação de custos ambientais. Neste contexto, 81\% das empresas afirmam não conhecer os custos ambientais sendo que, das que conhecem, nenhuma divulga tais informações publicamente.

Estes resultados caracterizam a amostra como um centro de oportunidades para desenvolvimento e aplicação de ferramentas inerentes à contabilidade ambiental, iniciando com o processo de identificação, mensuração, registro e evidenciação (interna e externa) de modo que tanto a entidade quanto a comunidade possa usufruir destas informações com vista a construção de maior transparência quanto ao uso dos recursos ambientais disponíveis na região. Sugere-se o desenvolvimento de parcerias de pesquisa entre as Instituições de Ensino Superior e as empresas de modo a aprofundar os estudos e sanar as lacunas 
apresentadas nesta pesquisa. Além disso, sugere-se que sejam realizados futuros estudos com vistas a identificar, na amostra, as razões internas de cada empresa que possam justificar a situação atual quanto à evidenciação de informações contábeis socioambientais.

\section{Referências}

Bornia, A. C. Mensuração das perdas dos processos produtivos: uma abordagem metodológica de controle interno. Florianópolis: Universidade Federal de Santa Catarina, 1995. (Tese de doutorado).

Braga, C.; Pinho, D. R. A evidenciação contábil ambiental. In: Braga, C. (Org.). Contabilidade ambiental: ferramenta para a gestão da sustentabilidade. São Paulo: Atlas, 2007. p. 68-71

Correia, J. J. A.; Silva, F. E. A.; Rodrigues, R. N. Evidenciação socioambiental de empresas siderúrgicas brasileiras entre 2011 e 2015: análise dos relatórios financeiros e de sustentabilidade. Revista Brasileira de Gestão Ambiental e Sustentabilidade, v. 4, n. 8, p. 327-341, 2017. https://doi.org/ $10.21438 /$ rbgas. 040808

Costa, M. J. A. Direito das obrigações. 6. ed. rev. atual. Coimbra: Almedina, 1994.

Deegan, C. The legitimizing effect of social and environmental disclosures: A theoretical foundation. Accounting, Auditing \& Accountability Journal, v. 15, n. 3, p. 282311, 2002. https://doi.org/10.1108/ 09513570210435852

Fenker, E. A.; Diehl, C. A.; Alves, T. W. Um estudo empírico sobre gestão de custos e riscos ambientais. Anais do XVI Congresso Brasileiro de Custos, Fortaleza, 2009.

Ferreira, A. C. S.; Carvalho, M. S. Um estudo sobre a evidenciação dos benefícios econômicos, sociais e ambientais da Central de Separação de Recicláveis (CSR) da Companhia de Limpeza Urbana da Cidade do Rio de Janeiro. ConTexto, v. 7, n. 11, 2007.

Ferreira, A. C. S. Contabilidade ambiental: uma informação para o desenvolvimento sustentável. 2. ed. São Paulo: Atlas, 2006.

Ferreira, J. S.; Rover, S.; Ferreira, D. D. M.; Borba, J.A. Informações financeiras ambientais: diferença entre o nível de disclosure entre empresas brasileiras. Revista de Educação e Pesquisa em Contabilidade, v. 10, n. 1, p. 5-24, 2016. https://doi.org/10.17524/repec.v10i1.1334

Ferreira, R. R.; Berner, C. V. Contabilidade Ambiental: método de auxílio na gestão e sustentabilidade. Revista Integralização Universitária, v. 11, n. 15, p. 28-39, 2016.

Fonseca, D.; Machado, D. G.; Costa, A. A.; Souza, M. A. Evolução da evidenciação de custos ambientais: um estudo em empresas do setor de papel e celulose-integrantes do Índice de Sustentabilidade Empresarial-ISE. Revista de Gestão Ambiental e Sustentabilidade, v. 5, n. 2, p. 34-48, 2016.

Freitas, J. L.; Pandolfo, A.; B'Ordignon, S.; Kurek, J. Custo ambiental: uma abordagem sobre o conceito e sua aplicação em uma indústria no processo de microfusão de aço. Anais do XIV Congresso Brasileiro de Custos, João Pessoa, 2007.

Freitag, V. C.; Ribeiro, S. P.; Lima, F.; Marques, J. L.; Araujo, J. L. S. Aplicabilidade da Contabilidade Ambiental nas indústrias química-farmacêuticas do Estado do Paraná. Revista Livre de Sustentabilidade e Empreendedorismo, v. 1, n. 1, p. 79-98, 2016.

Gil, A. C. Como elaborar projetos de pesquisa. 5. ed. São Paulo: Atlas, 2010.

Gray, R. The social accounting project and accounting organizations and society. Privileging engagement, imaginings, new accountings and pragmatism over critique? Accounting, Organizations and Society, v. 27 , n. 7, p. 687-708, 2002. https://doi.org/ 10.1016/S0361-3682(00)00003-9

Hendriksen, E. S; Van Breda, M. F. Teoria da Contabilidade. São Paulo: Atlas, 1999.

Iudícibus, S. Teoria da Contabilidade. 6. ed. São Paulo: Atlas, 2000.

Kraemer, M. E. P. Contabilidade ambiental como sistema de informações. Revista Brasileira de Contabilidade, v. 31, n. 133, p. $69-83,2002$.

Kraemer, M. E. P. Contabilidade Social: medindo a responsabilidade social. 2010. Disponível em: <http://gerencia.ambiente brasil.com.br/midia/anexos/456.pdf>.

Acesso em: 01 out. 2010. 
Kraemer, M. E. P. Contabilidade Ambiental: relatório para um futuro sustentável, responsável e transparente. 2006. Disponível em: <http://br.monografias.com/trabalhos/ contabilidade-ambiental/contabilidadeambiental.shtml>. Acesso em: 01 out. 2010.

Kroetz, C. E. S. Balanço social: teoria e prática. São Paulo: Atlas, 2000.

Laporta, R. Gestión de costos medioambientales y costos de no-producto. Anais do XVI Congresso Brasileiro de Custos, Fortaleza, 2009.

Leonardo, V. S. Um estudo sobre os gastos ambientais presentes na contabilidade de indústrias químicas brasileiras. Contabilidade Vista \& Revista, v. 17, n. 2, p. 89-109, 2006.

Leone, G.S. G. Custos: planejamento, implantação e controle. 3. ed. São Paulo: Atlas, 2000.

Likert, R. A technique for the measurement of attitudes. Archives of Psychology, v. 140, p.1-55, 1932. Disponível em: <https://legacy.voteview.com/pdf/Liker t_1932.pdf>. Acesso em: 25 abr. 2019.

Martins, R. M.; Campos, V. C. Guia prático para pesquisa científica. Rondonópolis: UNIR, 2004.

Melo, M. S.; Vieira, P. R. C. Imagem corporativa e investimento na preservação do meio ambiente: a nova tendência da agenda estratégica. Anais do XXVII ENANPAD, Atibaia, 2003.

Paiva, P. R. Contabilidade ambiental: evidenciação dos gastos ambientais com transparência e focada na prevenção. São Paulo: Atlas, 2006.
Parker, L. Twenty-one years of social and environmental accountability research: A coming of age. Accounting Forum, v. 35, n. 1, p. 1-10, 2011. https://doi.org/10.1016/ j.accfor.2010.11.001

Ribeiro, M. S. Contabilidade ambiental. São Paulo: Saraiva, 2006.

Ribeiro, R. B. Impacto da não-preservação ambiental no resultado de uma indústria têxtil da região metropolitana de Natal-RN. Revista Universo Contábil, v. 6 n. 3, p. 8095, 2010. https://doi.org/10.4270/ ruc.20106

Rossato, M. V. R.; Trindade, L. L.; Brondani, G. Custos ambientais: um enfoque para a sua identificação, reconhecimento e evidenciação. Revista Universo Contábil, v. 5 , n. 1, p. 72-87, 2009. https://doi.org/ 10.4270/ruc.20095

Tinoco, J. E. P. Balanço social: uma abordagem da transparência e da responsabilidade pública das organizações. São Paulo: Atlas, 2009.

Tinoco, J. E. P. Balanço social e o relatório de sustentabilidade. São Paulo: Atlas, 2010.

Tinoco, J. E. P.; Kraemer, M. E. P. Contabilidade e gestão ambiental. 3. ed. São Paulo: Atlas, 2011.

Vasconcelos, G.; Pimentel, M. S. Análise do disclosure dos custos e investimentos ambientais das empresas potencialmente poluidoras que compõem o Índice de Sustentabilidade Empresarial da Bovespa. Revista de Gestão Ambiental e Sustentabilidade, v. 7, n. 2, p. 210-229, 2018. 